\section{Germination Responses of Three Desert Grasses to Moisture Stress and Light ${ }^{1}$}

\section{CARLOS R. TAPIA ${ }^{2}$ AND ERVIN M. SCHMUTZ}

Graduate Student in Range Management and Range Management Specialist, Department of Watershed Management, University of Arizona, Tucson, Arizona.

\section{Highlight}

Lehmann lovegrass appeared very susceptible to physiological drought while Arizona cottontop and plains bristlegrass were not appreciably affected until osmotic tensions exceeded 12 atm. Lehmann lovegrass was the fastest and plains bristlegrass was the slowest to germinate. This study indicated that the adaptability and responsiveness of Lehmann lovegrass is due to its ability to germinate rapidly whereas the other two species require more time of moisture availability. Lehmann lovegrass and Arizona cottontop appeared adversely affected by constant darkness which suggests that they require a shallow planting while plains bristlegrass seemed to have the opposite response, which suggests that it requires a deeper planting.

Vast areas of rangcland in the Southwest and the arid lands of Mexico were formerly dominated by perennial grasses. These lands have deteriorated to brush and now badly need revegetation. If good grasses for reseeding these areas could be found, the productivity of the range could be increased, the soil losses would be diminished, and the range would be able to support more cattle and game. Artificial seeding is frequently recommended to improve these rangelands.

\footnotetext{
1 Paper No. 1666, Arizona Agricultural Experiment Station, Tucson. Paper is based on Masters' Thesis, University of Arizona, Tucson, 1970. Appreciation is expressed to the Department of Watershed Management of the University of Arizona and its faculty for their help in making this study. Received June 20,1970; accepted for publication December 1, 1970.

2 Present address is Bank of Mexico, Hermosillo, Sonora, Mexico.
}

To diminish the risk of seeding failure in arid climates, it is necessary to better understand the factors involved in the process of seed germination. Also, because species vary in their requirements for germination and growth it is necessary to study the responses of different species to arid conditions.

Because of erratic precipitation and high evapotranspiration in arid lands, the soil moisture is often inadequate for seed germination and seedling establishment. Therefore, seed germination and seedling establishment are the most critical phases in revegetation of arid lands.

Season of planting may also influence the success of a seeding practice and one of the main characteristics of any given season is day length (photoperiod). Light amount, kind and length of exposure contribute to the germination of most grass species and are factors which have often been neglected when planning a seeding program.

This study was designed to determine moisture and photoperiodic requirements of three desert grasses and to determine some of the factors affecting seeding success or failure. The grasses used were Lehmann lovegrass (Eragrostis lehmanniana Nees), plains bristlegrass (Setaria macrostachya H. B. K.), and Arizona cottontop (Trichachne californica (Benth.) Chase).

\section{Methods}

The seeds ${ }^{3}$ of Lehmann lovegrass and Arizona cottontop were grown in the Tucson Plant Material Center in 1963 and 1958, respectively, and the seeds of plains bristlegrass were obtained through the Tucson Plant Material Center from Tucumcari, New Mexico, and were grown there in 1960. The seeds used in this study were selected for size and uniformity as suggested by the studies of Kneebone and Cremer (1955) and Beveridge and Wilsie (1959). Because of the hard seed coat of plains bristlegrass, seeds were scarified by shaking for two minutes inside a cylinder lined with medium-textured sandpaper.

\footnotetext{
3 The word seed will be used instead of caryopsis or fruit in accordance with common custom.
} 


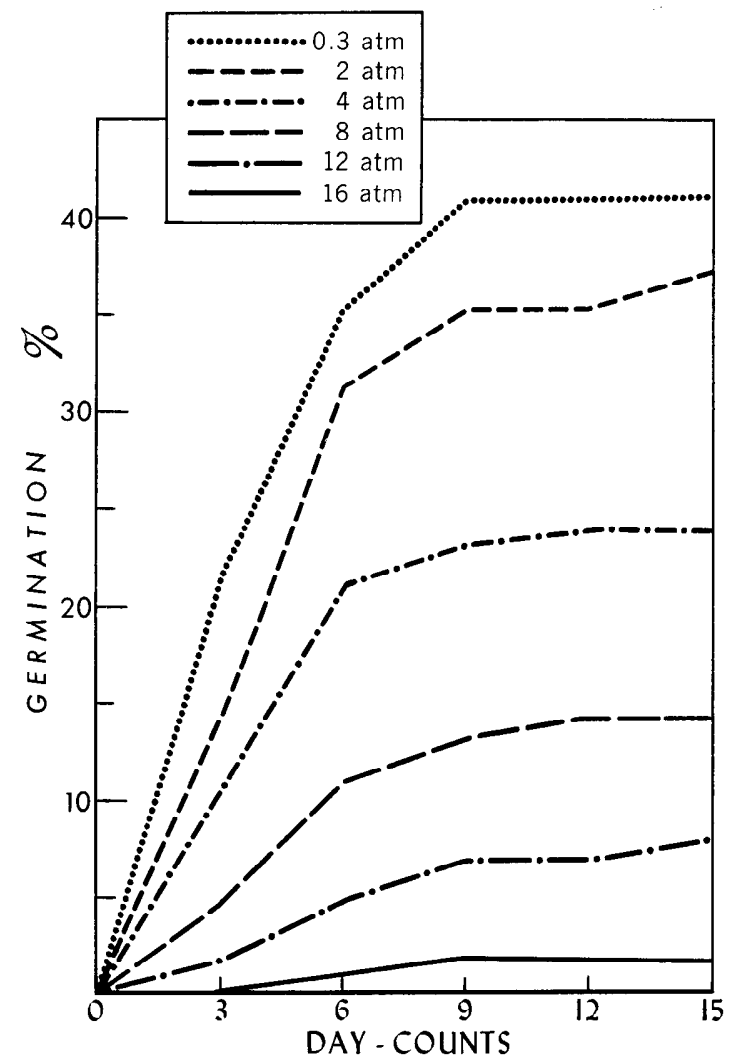

Fig. 1. Effects of mannitol-induced moisture stress on the germination of Lehmann lovegrass.

The experiment was conducted in a Stultz germinator regulated for constant light, $77 \mathrm{~F}$ temperature, and 90 to $100 \%$ relative humidity. The experimental design was a randomized block split-split plot design as outlined by Davies (1967). Germination tests were run for 15-day periods and repeated three times for replication. The three grass species were subjected to four light treatments and six moisture stress levels. Species were randomly assigned to position in the germinator, light treatments were assigned to rows of 6 petri dishes within each species, and the osmotic tensions were assigned to the petri dishes within each light treatment.

The light treatments consisted of constant light, 18 hours light and 6 hours dark, 18 hours dark and 6 hours light, and constant darkness. Day-length effects were simulated by painting petri dishes with a heavy coat of black paint to prevent light from reaching the seeds. When it was desired that light reach the seeds, the black cover of the petri dish was replaced with a transparent one.

The osmotic tensions were accomplished by saturating the substrata in the petri dishes with $0.3,2,4,8,12$ and 16 atm of D-mannitol $\left(\mathrm{C}_{8} \mathrm{H}_{8}(\mathrm{OH})_{8}\right)$. These solutions were prepared for specific moisture tensions by the use of the formula described by Helmerick and Pfeifer (1954). Since the osmotic concentration varies with temperature, all solutions were adjusted to $77 \mathrm{~F}$, the temperature of the germinator.

All petri dishes were placed on perforated aluminum trays set $7.5 \mathrm{~cm}$ apart to minimize heat due to respiration of the seeds. Counts were made on the third, sixth, ninth, and twelfth days for all petri dishes except the ones in constant darkness. These were counted along with all the rest on the fifteenth day.

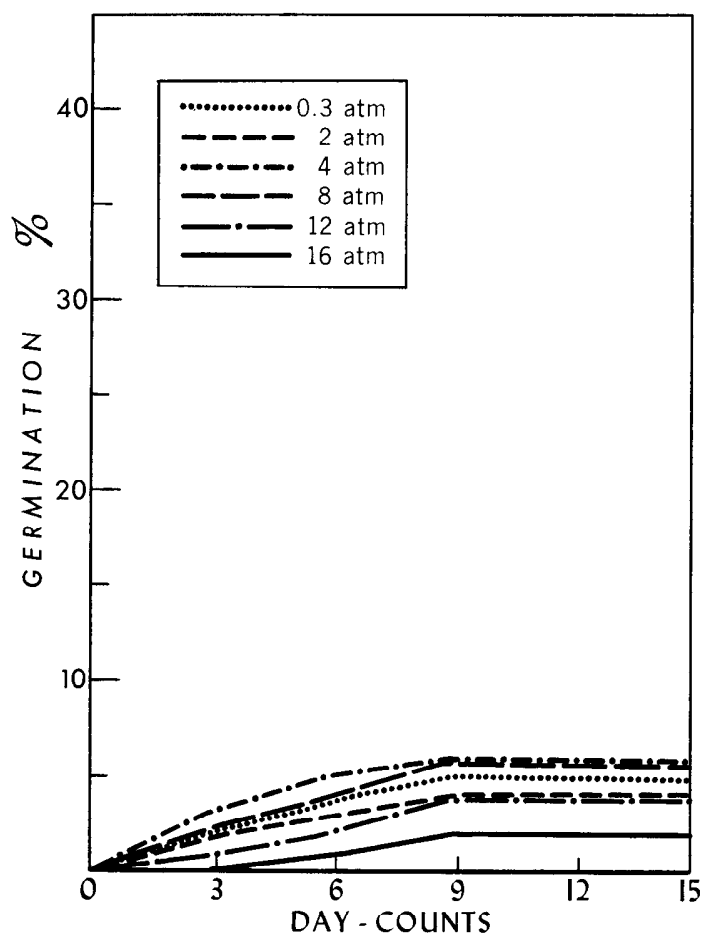

FIG. 2. Effects of mannitol-induced moisture stress on the germination of Arizona cottontop.

\section{Results and Discussion}

Results showed that the three grass species varied in their response to moisture stress and light.

\section{Moisture Stress}

The average germination percentagc of the thrce grass species as affected by moisture stress at $3,6,9$, 12 , and 15 days at three light treatments (excluding dark treatment) are presented in Figs. 1, 2, and 3. Germination of Lehmann lovegrass was the highest of the threc (up to $41 \%$ ). Germination of Arizona cottontop was very poor (below 6\%), which is unusual for this species but it is suspected that this effect was due to the age of the seeds, which was 12 years. Germination of plains bristlegrass was fair (up to $26 \%$ ); however, there was considerable variation among replications. This variation was probably due to differences in degree of scarification of the seeds used in the first replication and the ones used in the second and third.

Increases in osmotic tension delayed germination. In Lehmann lovegrass a delay in germination became apparent at 2 atm or more of osmotic tension, as shown by the slope of the lines in Fig. 1. In Arizona cottontop a consistent delay in germination does not appear until 16 atm of osmotic tension (Fig. 2). In plains bristlegrass a delay in germination was noticed at $4 \mathrm{~atm}$ and greater osmotic tensions at the 3-day count (Fig. 3). At the 6-day count, osmotic tensions of 2 atm and greater delayed germination, but the effect was apparently 


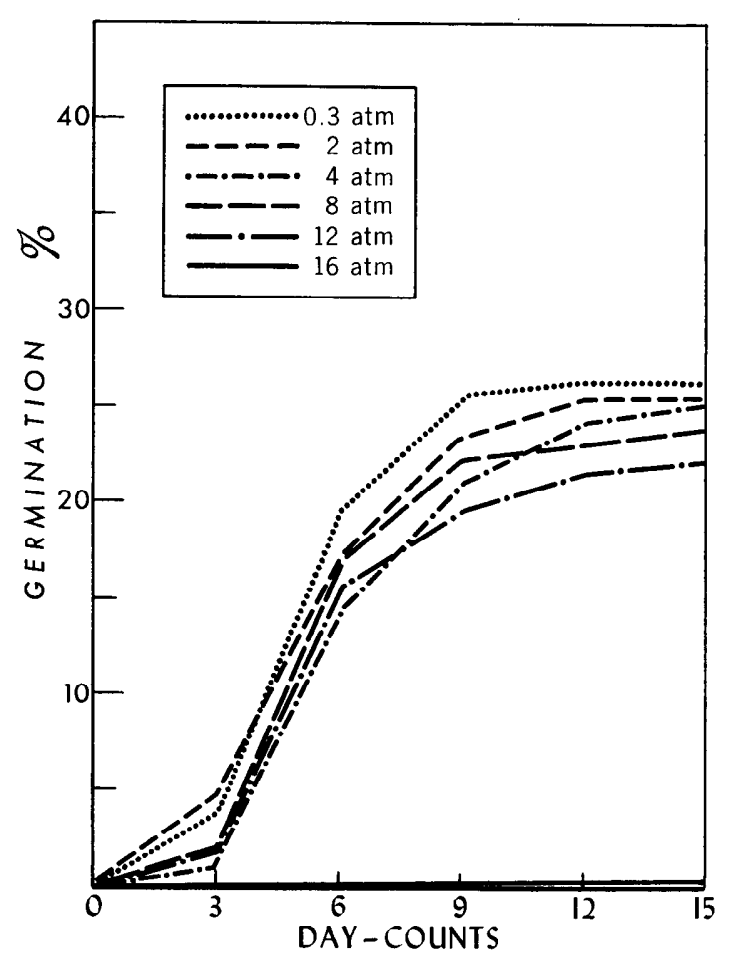

FIG. 3. Effects of mannitol-induced moisture stress on the germination of plains bristlegrass.

partially obscured by an inherent retardation of seed germination produced by the hard seed coat of this species. At $16 \mathrm{~atm}$ there was no germination.

Increases in osmotic pressure also decreased germination affecting most seriously Lehmann lovegrass, which showed an inverse correlation. These results were similar to those of Knipe and Herbel (1960) and Wilhem (1969). A test for linearity was run and was found significant at the $99 \%$ level which confirmed these results. Osmotic pressure also decreased the germination of Arizona cottontop (in part) and plains bristlegrass, but did not affect these species until the osmotic pressure exceeded $12 \mathrm{~atm}$. To test these results, orthogonal comparisons were run for linearity and curvilinearity (quadratic). Both species were found significant for curvilinearity, cottontop at the $99 \%$ level and plains bristlegrass at the $95 \%$ level, confirming that these species germinated well until 12 atm level of osmotic tension was reached and dropped sharply thereafter.

These results show that Lehmann lovegrass was not very tolerant to physiological drought since every increase in osmotic tension produced a decrease in germination. In contrast, the two native spccics, Arizona cottontop and plains bristlegrass, were quite resistant to physiological drought as the germination was not appreciably affected until osmotic tensions exceeded 12 atm.

The rapidity of germination in Lehmann lovegrass was excellent. It reached $50 \%$ of maximum
Table 1. The effect of light treatments on the 15-day germination (\%) totals of three grass species at $0.3 \mathrm{~atm}$ osmotic tension.

\begin{tabular}{lrrrc}
\hline \multicolumn{1}{c}{ Species } & $\begin{array}{c}\text { Continuous } \\
\text { light }\end{array}$ & $\begin{array}{c}\text { Long } \\
\text { day }\end{array}$ & $\begin{array}{c}\text { Short } \\
\text { day }\end{array}$ & $\begin{array}{c}\text { Continuous } \\
\text { darkness }\end{array}$ \\
\hline Lehmann lovegrass & 43 & 35 & 45 & 13 \\
Arizona cottontop & 7 & 4 & 4 & 2 \\
Plains bristlegrass & 18 & 30 & 31 & 48 \\
\hline
\end{tabular}

germination in three days and maximum germination in nine days. Arizona cottontop also reached maximum germination in nine days, but the total germination was less. Germination of plains bristlegrass was slowest, being only $20 \%$ of maximum after 3 days and not reaching maximum germination until the twelfth day.

\section{Light}

No significant differences were found that would indicate that day length affects in any way the germination of the three grasses (Table 1). Since the analysis showed a very large variance, it was decided to run an analysis for each individual species and investigate further the possible causes of such a large variance and also to see if the variance was masking any effects of the light treatments.

The problems during the experiment suspected as the sources of that variation were malfunctioning in the temperature regulating system of the germinator, age of the seeds of Arizona cottontop, fungi and micelia infestation, and different degrees of scarification of seeds of plains bristlegrass.

The analysis of Lehmann lovegrass showed a trend towards a decrease in germination under constant darkness at the $90 \%$ level. This result is substantiated by the findings of Brauen (1967), who stated, "Germination of seeds of Lehmann lovegrass was usually promoted by dark induction during inbibition. Dark induction must be followed by light induction and seeds were never harmed by dark induction of less than twenty-four hours. When light was given after periods of greater than twenty-four hours, germination was decreased with light sensitive accessions."

The analysis for Arizona cottontop showed a trend for decreased germination under constant darkness at the $80 \%$ level. It was suspected that the age of the seed lot contributed to this situation. Knipe (1969) stated, "Generally germination decreases with age for most species," and Tiedemann and Pond (1967), found that germination of twentyfive-year-old seeds of Arizona cottontop was only $25 \%$. These facts suggest that more experimentation of this kind is required with Arizona cottontop using more viable seeds.

The analysis for plains bristlegrass revealed the greatest amount of variation. It is suspected that 
this was due to different degrees of seed scarification between the first and the other two replications. Nevertheless, when examining the average total means, it reveals a tendency towards increased germination with increasing dark periods, a result similar to Knipe's (1969) when working with alkali sacaton. It is probable that the sources of variation described above might have masked this result, so it is suggested that a similar study of plains bristlegrass be done under more refined conditions.

\section{Conclusions}

Because Lehmann lovegrass was less resistant to physiological drought than the two native species, the key to its adaptability appears to be due to its ability to germinate rapidly rather than its ability to withstand drought conditions. This fact is substantiated by the findings of Jordan (1965) who found that under extreme conditions (under 9 inches annual rainfall) established Lehmann lovegrass was subject to high death loss whereas Arizona cottontop and plains bristlegrass survival was high. In the arid Southwest, precipitation is very low and available moisture exists for only short periods of time. Lehmann lovegrass seems to be able to utilize this moisture to germinate and take root before the moisture is lost, whereas plains bristlegrass and Arizona cottontop need six to nine days of good moisture, which occurs rarely in the arid Southwest. Therefore, it would be expected that Arizona cottontop and plains bristlegrass would become established in a year of very good moisture and stay there if not grazed out. In contrast Lehmann lovegrass would probably become established in years of average or better precipitation, and if the stand is lost during a bad ycar, it will come back when moisture conditions improve.

Lehmann lovegrass and Arizona cottontop appear to be adversely affected by constant darkness, whereas with plains bristlegrass darkness seems to improve germination. If further research confirms these results, it would indicate that Lehmann lovegrass and Arizona cottontop require a shallow planting, whereas plains bristlegrass would require a deep planting.

\section{Literature Cited}

Beveridge, J. L., ANd C. P. Wilsie. 1959. Influence of depth of planting, seed size, and variety on emergence and seeding vigor in alfalfa. Agron. J. 51:731-734.

Brauen, E. S. 1967. Seed coat histology, germination, dormancy and seedling drought tolerance of Lehmann lovegrass, Eragrostis lehmanniana Nees. Ph.D. Diss., Univ. Arizona, Tucson. $148 \mathrm{p}$.

Davies, O. L. 1967. Design and analysis of industrial experiments. 2nd ed. Hafner Pub. Co., New York. 636 p.

HELMerick, R. H., AND R. P. Pfeifer. 1954. Differential varietal responses of winter wheat germination and early growth to controlled limited moisture conditions. Agron. J. 46:560-562.

JoRDAN, G.L. 1965. The evaluation of seedbeds, method of seeding, and species for reseeding arid rangelands of Arizona. Univ. Arizona Dep. Watershed Manage. Prog. Rep. 53 p.

Kneebone, W. R., and C. L. Cremer. 1955. The relationship of seed size to seedling vigor in some native grass species. Agron. J. 47:472-477.

Knipe, O. D., AND C. H. Herbel. 1960. The effects of limited moisture on germination and growth of six grass species. J. Range Manage. 13:297-301.

KNIPE, O. D. 1969. Factors affecting the germination of alkali sacaton (Sporobolus airoides Torr.). Ph.D. Diss., Univ. Arizona, Tucson. $82 \mathrm{p}$.

Tiedemann, A. R. And F. W. Pond. 1967. Viability of grass seed after long periods of uncontrolled storage. J. Range Manage. 20:261-262.

WILHEM, M. J. 1969. Germination and seedling growth as affected by alternate wetting and drying of seeds of Eragrostis lehmanniana Nees. M. S. Thesis, Univ. Arizona, Tucson. $55 \mathrm{p}$.

\section{REPRINTS}

Reprints of articles appearing in the Journal of Range Management may be obtained from the author(s). Request for reprints should be sent to the author at his address indicated in the article head or accompanying footnote.

Reprints are not available from the editor or from the Society's office.
CLYDE ROBIN

$$
\text { NATIVE SEEDS }
$$

Castro Valley, California 94546 